\title{
Highly efficient and chemoselective oxidation of sulfides catalyzed by iron(III) corroles with iodobenzene diacetate
}

\author{
Tse-Hong Chen, ${ }^{\S}$ Ka Wai Kwong, Ngo Fung Lee, Davis Ranburger and Rui Zhang* \\ Department of Chemistry, Western Kentucky University, Bowling Green, KY 42101, USA \\ * Corresponding author: Rui Zhang, Department of Chemistry, Western Kentucky University, \\ 1906 College Heights Blvd \#11079, Bowling Green, KY 42101 \\ ${ }^{\S}$ Current address: Department of Chemistry, Purdue University, West Lafayette, IN
}

Phone: 270-745-3803, Fax: 270-745-5361, e-mail: rui.zhang@wku.edu 


\begin{abstract}
Iron(III) corrole complexes catalyze the highly chemoselective oxidation of sulfides to sulfoxides with iodobenzene diacetate $\left[\mathrm{PhI}(\mathrm{OAc})_{2}\right]$ as a mild oxygen source. Various substituted thioanisoles, vinyl sulfides, and hydroxyl sulfides can be efficiently oxidized to sulfoxides with quantitative conversions (up to 5000 TONs) and excellent selectivies without over-oxidation to sulfones. The remarkably enhanced catalytic activity and stability against degradation is ascribed to the slow and steady-state formation of $\mathrm{PhIO}$ from highly soluble $\mathrm{PhI}(\mathrm{OAc})_{2}$ in the presence of a small amount of water. On the basis of Hammett correlation and mixing UV-vis spectral studies, a putative high-valent iron(V)-oxo species is likely generated as a short-lived active intermediate.
\end{abstract}

\title{
Keys words
}

Iron(III) corrole; oxidation; iodobenzene diacetate; sulfide; sulfoxide 


\section{Introduction}

Catalytic oxidation is a pivotal transformation for the synthesis of high-value chemicals and the search for versatile and selective reagents for catalytic oxidations under mild conditions have been centers of research interest for decades.[1,2] In this context, many transition metal catalysts [3-6] have been extensively synthesized and studied as models to probe the sophisticated molecular oxygen activation and/or mimic the ubiquitous cytochrome P450s in Nature. [7] Notably the selective oxidation of sulfides to sulfoxides (sulfoxidation) is of great significance because organic sulfoxides are valuable synthetic intermediates for the production of natural products and biologically significant molecules.[8] Optically active sulfoxides also play important roles in medicinal and pharmaceutical chemistry for the preparation of the therapeutic agents such as antiulcer (proton pump inhibitors), antibacterial, antifungal, antihypertensive and cardiotonic agents, as well as psychotonics and vasodilators.[9] A large range of electrophilic reagents such as peracids, hyperchlorites, periodates and highly toxic oxo metal oxidants have been applied for the oxidation of conventional sulfides.[2, 10-14]. In almost all catalytic sulfoxidations reported, the most common oxygen source is hydrogen peroxide $\left(\mathrm{H}_{2} \mathrm{O}_{2}\right)$ because it is inexpensive, ecofriendly and readily available.[2, 11] To date, various catalysts including metal complexes, polyoxometalates, and flavins have been reported in the literature for the catalytic oxidation of sulfides to sulfoxides with $\mathrm{H}_{2} \mathrm{O}_{2} \cdot[15-18]$ However, some of them cause the over-oxidation to sulfones and the procedures that are reported rarely provide the ideal combination of high selectivity for oxidation to sulfoxide, fast reaction, and excellent product yields.

Owing to discoveries of facile synthesis of 19-membered macrocyclic triarylcorroles,[19, 20] metallocorroles including meso- $N$-substituted triazocorroles(corrolazines) have attracted considerable interest in their catalytic properties in view of their similarity to metalloporphyrins.[2125] Being tri-anionic, corrole ligand is capable of accessing higher metal-oxo species which are 
inherently more stable than the corresponding porphyrin-metal-oxo species.[26-28] Thus, a large number of metallocorroles have been prepared and exploited in a wide variety of catalytic oxidations.[21-23] In 1999, Gross and coworkers reported the first example of catalytic oxidation with the iron(IV) complex of tris(pentafluorophenyl)corrole $\left(\mathrm{H}_{3} \mathrm{TPFC}\right)$ using iodosobenzene $(\mathrm{PhIO})$ as the sacrificial oxidant.[29] Later, biomimetic oxidations with $\mathrm{Mn}^{\mathrm{III}}$ (TPFC),[26] albuminconjugated manganese,[30] and chromium corroles[31] were also studied by the same group of authors. Perhalogenation of the corrole macrocycle with bromine or fluorine results in increased reactivity for the corrole-manganese complexes under catalytic conditions with PhIO.[32, 33] Catalytic aerobic oxidations by a fluorinated iron(IV) $\mu$-oxo biscorrole through a photodisproportionation pathway was also reported.[34] Nevertheless, in many cases, the use of metallcorroles for catalytic oxidations has met with limited success in view of the poor selectivity, low efficiency and inherent catalyst degradation.

In contrast to the sacrificial oxidants in common use for metal-catalyzed reactions, iodobenzene diacetate, $\mathrm{PhI}(\mathrm{OAc})_{2}$, has been less often employed due to its mild oxidizing ability.[35-37] In general, $\mathrm{PhI}(\mathrm{OAc})_{2}$ does not show appreciable reactivity towards organic sulfides nor damage the metal catalysts under the usual catalytic conditions. This is particularly beneficial for metallocorrole-catalyzed oxidations because metallocorroles are less robust and prone to oxidative degradation. Very recently, we discovered an efficient oxidation of alkenes with $\mathrm{PhI}(\mathrm{OAc})_{2}$ catalyzed by an electron-deficient iron(III) corrole.[38] In this work, we further explore the usefulness of $\mathrm{PhI}(\mathrm{OAc})_{2}$ for the efficient and chemoselective oxidation of sulfides using iron corrole catalysts. In most cases, substituted thioanisoles, various vinyl sulfides and hydroxyl sulfides have been successfully oxidized to the corresponding sulfoxides with quantitative conversions and excellent chemoselectivities for sulfoxides. 


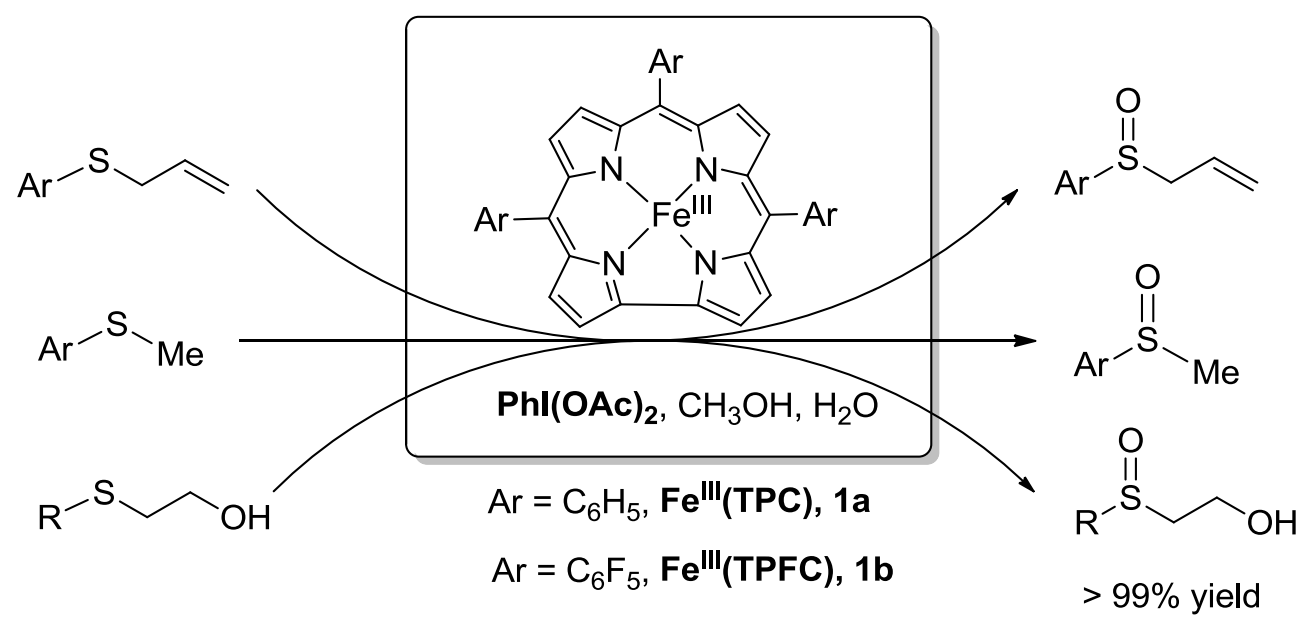

Scheme 1. Catalytic sulfoxidations by iron(III) corrole in the presence of $\mathrm{PhI}(\mathrm{OAc})_{2}$ and water

\section{Experimental}

\subsection{Materials}

All commercial reagents were of the best available purity and used as supplied unless otherwise specified. Iodobenzene diacetate or (diacetoxyiodo)benzene, $\mathrm{PhI}(\mathrm{OAc})_{2}$, was purchased from Aldrich Chemical Co. and used as such. $m$-Chloroperoxybenzoic acid ( $m$-CPBA) (77\%) from Aldrich Chemical Co. was purified by precipitation-crystallization from methylene chloride and $n$ hexane, and then dried in vacuum. Iodosobenzene (PhIO) and tert-butyl hydroperoxide (TBHP) were purchased from TCI America Co. and was used as obtained. All reactive substrates of organic sulfides for catalytic oxidations were passed through a dry column of active alumina (Grade I) before use. Pyrrole (98\%), benzaldehyde and pentafluorobenzaldehyde from Sigma-Aldrich Chemical Company were distilled prior to use.

Corrole free ligands used in this study, including 5,10,15-triphenylcorrole $\left(\mathrm{H}_{3} \mathrm{TPC}\right)$ [39] and 5,10,15-tripentafluorophenylcorrole ( $\mathrm{H}_{3}$ TPFC),[20] were prepared according to the reported procedures, and their characterization data $\left({ }^{1} \mathrm{H}\right.$ NMR and UV-vis) was consistent with reported 
values. The corrole-iron(III) dietherate complexes were prepared as previously described.[40] In a typical procedure, a solution of $\mathrm{H}_{3}$ TPC or $\mathrm{H}_{3}$ TPFC $(50 \mathrm{mg}, 63 \mu \mathrm{mol})$ and a large excess of iron(II) chloride (125 mg, $1.4 \mathrm{mmol}$ ) in dry DMF under argon was heated at reflux for $60 \mathrm{~min}$. Evaporation of solvent followed by column chromatography on silica gel (diethyl ether) resulted in isolation of the corresponding $\mathrm{Fe}^{\mathrm{III}}(\mathrm{Cor})\left(\mathrm{OEt}_{2}\right)_{2}$ in $>90 \%$ yields. The UV-vis spectra of $\mathrm{Fe}^{\mathrm{III}}(\mathrm{Cor})\left(\mathrm{OEt}_{2}\right)_{2}$ were shown in the Fig S1 of the supporting information. Following the known procedure,[40, 41] the fluorinated diiron(IV) $\mu$-oxo biscorrole, formulated as $\left[\mathrm{Fe}^{\mathrm{IV}}(\mathrm{TPFC})\right]_{2} \mathrm{O}$ and $\mathrm{Fe}^{\mathrm{IV}}(\mathrm{TPFC}) \mathrm{Cl}$ were synthesized by aerobic oxidation of $\mathrm{Fe}^{\mathrm{III}}(\mathrm{TPFC})\left(\mathrm{OEt}_{2}\right)_{2}$ in different solutions. Iron(III)

pentafluorophenyl porphyrin chloride, i.e. Fe ${ }^{\mathrm{III}}(\mathrm{TPFPP}) \mathrm{Cl}$ used for catalytic sulfoxidations for comparison, was obtained from Sigma Aldrich Co and used as such. All these known iron complexes were characterized by UV-vis, IR and ${ }^{1} \mathrm{H}$ NMR spectra that matched those previously reported.

\subsection{Instrumentation}

UV-vis spectra were recorded on an Agilent 8453 diode array spectrophotometer. ${ }^{1} \mathrm{H}$ NMR was performed on a JEOL ECA-500 MHz spectrometer at 298K with tetramethylsilane (TMS) as internal standard. Chemical shifts (ppm) are reported relative to TMS. Gas chromatograph analyses were conducted on an Agilent GC-7820A/MS-5975 equipped with a flame ionization detector (FID) using a J\&W Scientific Cyclodex-B (chiral) capillary column. The above GC-MS system is also coupled with an auto sample injector. Reactions of $\mathrm{Fe}^{\mathrm{III}}(\mathrm{Cor})$ with excess of $\mathrm{PhI}(\mathrm{OAc})_{2}$ were conducted in a anaerobic methanol solution at $23 \pm 2{ }^{\circ} \mathrm{C}$.

\subsection{General procedure for catalytic oxidations}

Unless otherwise specified, all catalytic reactions were typically carried out in the presence of a small amount of $\mathrm{H}_{2} \mathrm{O}(4.5 \mu \mathrm{L}$ ) with $1 \mu \mathrm{mol}$ of catalyst (ca. $0.2 \mathrm{~mol} \%$ ) in $2 \mathrm{~mL}$ of methanol 
containing $0.5 \mathrm{mmol}$ of organic substrates. $\mathrm{PhI}(\mathrm{OAc})_{2}(0.75 \mathrm{mmol}, 1.5$ equiv. $)$ was then added to the reaction solution at $23 \pm 2{ }^{\circ} \mathrm{C}$. Aliquots of the reaction solution at constant time intervals were analyzed by ${ }^{1} \mathrm{H}$ NMR together with GC-MS to determine the conversions, formed products and yields with an internal standard (1,2,4-trichlorobezene). The internal standard was shown to be stable under the oxidation conditions in control reactions. The pure products were isolated by a flash column chromatography (silica gel with $\mathrm{CH}_{2} \mathrm{Cl}_{2}$ and hexane mixture) to give isolated yields (Table 3, entry 1, 2 and 6). All reactions were performed 2 to 3 times, and the data reported represents the average of these reactions.

\subsection{Hammett correlation studies}

A $\mathrm{CH}_{3} \mathrm{OH}$ solution containing equal amounts of two substrates, e.g. thioanisole $(0.5 \mathrm{mmol})$ and substituted thioanisoles $(0.5 \mathrm{mmol})$, iron(III) corrole catalyst $(1 \mu \mathrm{mol})$ and an internal standard of 1,2,4-trichlorobenzene $(0.1 \mathrm{mmol})$ was prepared (final volume $=2 \mathrm{~mL}) . \mathrm{PhI}(\mathrm{OAc})_{2}(0.2 \mathrm{mmol})$ as limiting reagent, was added and the mixture was stirred at ambient temperature $\left(23 \pm 2{ }^{\circ} \mathrm{C}\right)$ in the presence of a small amount of $\mathrm{H}_{2} \mathrm{O}(4.5 \mu \mathrm{L})$ for $10 \mathrm{~min}$. Relative rate ratios for catalytic oxidations were determined by GC based on the amounts of sulfoxide products as measured against an internal standard. In this work, all the catalytic sulfoxidations proceeded with good yields $(>99 \%)$, mass balance $(>95 \%)$, and in all cases no traces of sulfones were detected. Thus, the ratio of product formation should reasonably reflect the relative sulfide reactivity toward the corrole-iron-catalyzed oxidation.

\section{$3 \quad$ Results and Discussion}

\subsection{Screening studies in the catalytic oxidation of thioanisole}


Although the $\mathrm{PhI}(\mathrm{OAc})_{2}$ has been used as a mild oxygen source for some time, apparently it had hitherto not been employed for iron corrole-catalyzed sulfoxidation reactions. Thus, the usefulness of $\mathrm{PhI}(\mathrm{OAc})_{2}$ was first evaluated in the catalytic oxidation of thioanisole (2a) by iron(III) corrole catalysts (1) that differ in electronic environment. In order to work under homogeneous conditions and follow the analysis by ${ }^{1} \mathrm{H}-\mathrm{NMR}$, catalytic reactions were performed in $\mathrm{CD}_{3} \mathrm{OD}$ at room temperature with a $0.2 \mathrm{~mol} \%$ catalyst loading and a 1:1.5 ratio of thioanisole and $\mathrm{PhI}(\mathrm{OAc})_{2}$. Previous studies discovered that a small of amount of water with $\mathrm{PhI}(\mathrm{OAc})_{2}$ as oxygen source gave an accelerating effect in the iron(III) porphyrin/corrole-catalyzed epoxidations.[36, 38] Therefore, to evaluate the water effect, the sulfoxidation reactions by iron(III) triphenylcorrole (1a) were carried out in the presence and absence of water. The time courses of oxidation reactions are depicted in Figure 1 and screening results are compiled in Table 1. In the absence of water, the reaction was relatively slow and 60\% conversion of sulfide was observed after $1 \mathrm{~h}$ (entry 1 in Table 1). Remarkably, the same reaction proceeded more rapidly with a small amount of $\mathrm{H}_{2} \mathrm{O}(4.5 \mu \mathrm{L})$, and thus, $100 \%$ conversion was obtained within $1 \mathrm{~h}$ at ambient temperature (entry 2 in Table 1 ). As suggested in early studies, the water can gradually induce the formation of more oxidizing $\mathrm{PhIO}$ from the $\mathrm{PhI}(\mathrm{OAc})_{2}$.[36] Furthermore, addition of $\mathrm{H}_{2} \mathrm{O}$ in the oxidation reaction allows for the release of stable $\mathrm{HOAc}$ (detected by $\mathrm{GC}$ ) instead of anhydride $\mathrm{Ac}_{2} \mathrm{O}$ under anhydrous conditions, resulting in a faster reaction. In addition, previous studies indicate that the access of oxygen source to the metal center of catalyst is crucial to the catalytic activity.[42] As a dissociating solvent, water may help removal of the axial ligand and bind the oxygen source, in this case $\mathrm{PhI}(\mathrm{OAc})_{2}$, more efficiently to the metal center. Importantly, methyl phenyl sulfoxide (3a) was the only identifiable product (> $99 \%$ by GC) without the over-oxidation product methyl phenyl sulfone (4a), which manifests the high chemoselectivity of this oxidation. Increasing the amount of water could enhance 
the catalytic activity further, albeit considerably reduce the chemoselectivity by formation of significant amount of sulfone (entry 3).

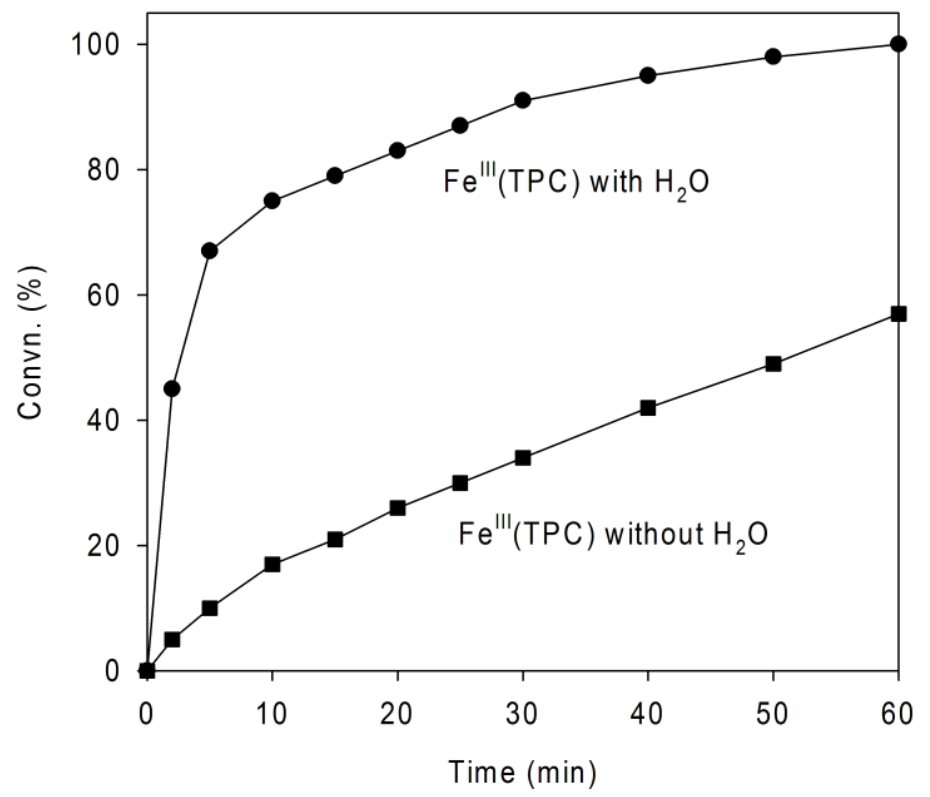

Fig. 1. Time courses of oxidation of thioanisole $(0.5 \mathrm{mmol})$ with $\mathrm{PhI}(\mathrm{OAc})_{2}(0.75 \mathrm{mmol})$ in $\mathrm{CD}_{3} \mathrm{OD}$ $(2 \mathrm{~mL})$ at room temperature catalyzed by $\mathrm{Fe}^{\mathrm{III}}(\mathrm{TPC})(\mathbf{1 a}, 1.0 \mu \mathrm{mol})$ in the presence (circle) or absence (square) of $\mathrm{H}_{2} \mathrm{O}(4.5 \mu \mathrm{L})$. Aliquots were taken at selected time intervals for product analyses with GC.

Table 1. Catalytic oxidation of thioanisole by iron corroles with iodobenzene diacetate ${ }^{a}$

\begin{tabular}{|c|c|c|c|c|c|c|c|}
\hline \multirow[b]{2}{*}{ Entry } & \multirow{2}{*}{$\begin{array}{r}\mathrm{Ph}^{-\mathrm{S}_{-}} \\
\mathbf{2 a}\end{array}$} & $\begin{array}{r}\text { Phl(OAc } \\
\text { Solve }\end{array}$ & $\begin{array}{l}5 \text { eqiv.) } \\
5^{\circ} \mathrm{C}\end{array}$ & & Me & & $\mathrm{Me}$ \\
\hline & & Solvent & $\begin{array}{l}\mathrm{H}_{2} \mathrm{O} \\
(\mu \mathrm{L})\end{array}$ & $\begin{array}{l}\text { Time } \\
\text { (h) }\end{array}$ & $\begin{array}{l}\text { Convn. } \\
(\%)^{b}\end{array}$ & $\begin{array}{l}\mathrm{Mb} \\
(\%)^{\mathrm{b}}\end{array}$ & $\begin{array}{l}\text { Selectivity } \\
(\mathbf{3 a}: \mathbf{4 a})^{\mathrm{b}}\end{array}$ \\
\hline 1 & $\mathrm{Fe}^{\mathrm{IIII}}(\mathrm{TPC})$ & $\mathrm{CD}_{3} \mathrm{OD}$ & 0 & 1 & 60 & $>95$ & $>99: 1$ \\
\hline 2 & & & 4.5 & 1 & 100 & $>95$ & $>99: 1$ \\
\hline 3 & & & 9.0 & 0.5 & 100 & $>95$ & $79: 21$ \\
\hline 4 & & $\mathrm{CDCl}_{3}$ & 0 & 1 & 7 & $>95$ & $>99: 1$ \\
\hline
\end{tabular}




\begin{tabular}{|c|c|c|c|c|c|c|c|}
\hline 5 & & $\mathrm{CD}_{3} \mathrm{CN}$ & 0 & 1 & 5 & $>95$ & $>99: 1$ \\
\hline 6 & $\mathrm{Fe}^{\mathrm{III}}(\mathrm{TPFC})$ & $\mathrm{CD}_{3} \mathrm{OD}$ & 0 & 1 & 20 & $>95$ & $>99: 1$ \\
\hline 7 & & $\mathrm{CD}_{3} \mathrm{OD}$ & 4.5 & 3 & 100 & $>95$ & $>99: 1$ \\
\hline $8^{c}$ & & $\mathrm{CD}_{3} \mathrm{OD}$ & 4.5 & 7 & 100 & $>95$ & $>99: 1$ \\
\hline 9 & {$\left[\mathrm{Fe}^{\mathrm{IV}}(\mathrm{TPFC})\right]_{2} \mathrm{O}$} & $\mathrm{CD}_{3} \mathrm{OD}$ & 0 & 1 & 17 & $>95$ & $>99: 1$ \\
\hline 10 & $\mathrm{Fe}^{\mathrm{IV}}(\mathrm{TPFC}) \mathrm{Cl}$ & $\mathrm{CD}_{3} \mathrm{OD}$ & 0 & 1 & 50 & $>95$ & $>99: 1$ \\
\hline 11 & $\mathrm{Fe}^{\mathrm{III}}(\mathrm{TPFPP}) \mathrm{Cl}$ & $\mathrm{CD}_{3} \mathrm{OD}$ & 4.5 & 1 & 100 & $>95$ & 95:5 \\
\hline \multicolumn{8}{|c|}{$\begin{array}{l}{ }^{a} \text { All reactions were performed in solvent }(2 \mathrm{~mL}) \text { at ca. } 23{ }^{\circ} \mathrm{C} \text { with a } 1: 1.5 \text { molar ratio of thioanisole } \\
\text { versus } \mathrm{PhI}(\mathrm{OAc})_{2} \text { and } 0.2 \mathrm{~mol} \% \text { catalyst at an initial substrate concentration of } 0.25 \mathrm{M} \text {. } \\
{ }^{\mathrm{b}} \text { Conversions (convn.), mass balance }(\mathrm{mb}) \text { and product selectivity were determined by }{ }^{1} \mathrm{H} \text { NMR } \\
\text { (JEOL } 500 \mathrm{M}) \text { and quantitative } \mathrm{GC}-\mathrm{MS} \text { analysis with an internal standard }(1,2,4 \text {-trichlorobenzene) } \\
\text { on the crude reaction mixture after the reaction is quenched by sodium hydroxide solution } \\
\left(\text { consuming all } \mathrm{PhI}(\mathrm{OAc})_{2}\right) \text {. }\end{array}$} \\
\hline
\end{tabular}

Possibly due to the low solubility of $\mathrm{PhI}(\mathrm{OAc})_{2}$, the use of other solvents such as $\mathrm{CDCl}_{3}$ or $\mathrm{CD}_{3} \mathrm{CN}$ instead of $\mathrm{CD}_{3} \mathrm{OD}$ resulted in reduced activity (Table 1, entries 4 and 5). The electrondeficient catalyst $\mathrm{Fe}^{\mathrm{III}}(\mathrm{TPFC})(\mathbf{1 b})$, which has been used as robust catalyst in many oxidation reactions, was less reactive compared to less electron-demand 1a, and a prolonged reaction time (3h) was required to obtain $100 \%$ conversion of $2 a$ (entries 6 and 7). For the two corrole systems studied here, the triphenylcorrole complex 1a with lower oxidation potential was apparently reacting faster with $\mathrm{PhI}(\mathrm{OAc})_{2}$. This observation suggested that the rate-determining step in the iron(III)-corrole system is the oxygen atom transfer from $\mathrm{PhI}(\mathrm{OAc})_{2}$ and not from the oxidizing intermediate (proposed iron-oxo corrole) to the sulfide substrate. Remarkably, the catalyst loading of the robust $\mathbf{1 b}$ can be as low as $0.02 \mathrm{~mol} \%$ (entry 8 ) without loss of activity, illustrating an unequivocally high catalytic efficiency (5,000 TON!). In terms of different oxidation states of iron 
catalyst, $\left[\mathrm{Fe}^{\mathrm{IV}}(\mathrm{TPFC})\right]_{2} \mathrm{O}$ and $\mathrm{Fe}^{\mathrm{IV}}(\mathrm{TPFC}) \mathrm{Cl}$ gave similar catalytic activities (Table 1, entries 9 and 10) in comparison to $\mathbf{1 b}$, which indicated that the oxidation state of iron(IV) is also accessible for generation of the active oxidizing species. With respect to the sulfoxidation of 2a under identical reaction conditions, $\mathrm{Fe}^{\mathrm{III}}(\mathrm{TPC})$ or $\mathrm{Fe}^{\mathrm{III}}(\mathrm{TPFC})$ performs as well as one of the best porphyrin catalysts known Fe $\mathrm{F}^{\mathrm{III}}$ (TPFPP)Cl [TPFPP = tetrakis(pentafluorophenyl)porphinato] (entry 11).[36] Control experiments showed that no sulfoxide was formed in the absence of either the catalyst or the $\mathrm{PhI}(\mathrm{OAc})_{2}$ even at elevated temperature $\left(50{ }^{\circ} \mathrm{C}\right)$, or in the presence of $\mathrm{PhI}(\mathrm{OAc})_{2}$ and water without catalyst (data not shown).

\subsection{Comparison of various oxygen sources in the catalytic oxidation of thioanisole}

The promising results with the $\mathrm{PhI}(\mathrm{OAc})_{2}$ in Table 1 prompted us to screen other commonly used oxygen sources in the iron(III) corrole-catalyzed oxidation of thioanisole under identical experimental conditions for the intended purpose of comparison. The representative results shown in Table 2 demonstrated that the mild oxygen source $\mathrm{PhI}(\mathrm{OAc})_{2}$ was especially effective in the iron(III) corrole-catalyzed selective oxidation of sulfide to sulfoxide (entry 1). In particular, $\mathrm{PhI}(\mathrm{OAc})_{2}$ shows great advantage in enhancing corrole catalyst stability against the catalytic degradation owing to its mild oxidizing ability. Monitoring catalytic reactions by UV-vis spectroscopy showed no significant catalyst bleaching in the end of reactions. Although $\mathrm{PhIO}$ or organic peroxide is a common oxygen source generally used in metal-catalyzed oxidations, it was found that the use of PhIO or tert-butly hydroperoxide (TBHP) under the same conditions led to a lower catalytic activity (entries 2 and 3). $m$-Chloroperoxybenzoic acid ( $m$-CPBA) gave a moderate conversion albeit with undesirable sulfone formation (entry 4). $\mathrm{H}_{2} \mathrm{O}_{2}$ as the oxygen source gave only $12 \%$ conversion (entry 5 ) and the catalyst was also found to be bleached during the reaction (>90\% bleaching in the end of reaction as indicated by UV-vis spectroscopy). The most likely explanation 
is that these oxygen sources with greater oxidizing abilities might accelerate the degradation of the iron(III) corrole catalysts as well as facilitate the over oxidation of sulfide to sulfone. Similar results were also observed in our previous work of selective epoxidation catalyzed by iron corrole

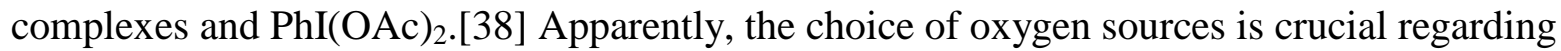
catalyst stability and reactivity in metallocorrole-mediated oxidations.

Table 2. Catalytic oxidation of thioanisole by iron(III) corrole (1a) with various oxygen sources in the absence of $\mathrm{H}_{2} \mathrm{O}^{\mathrm{a}}$

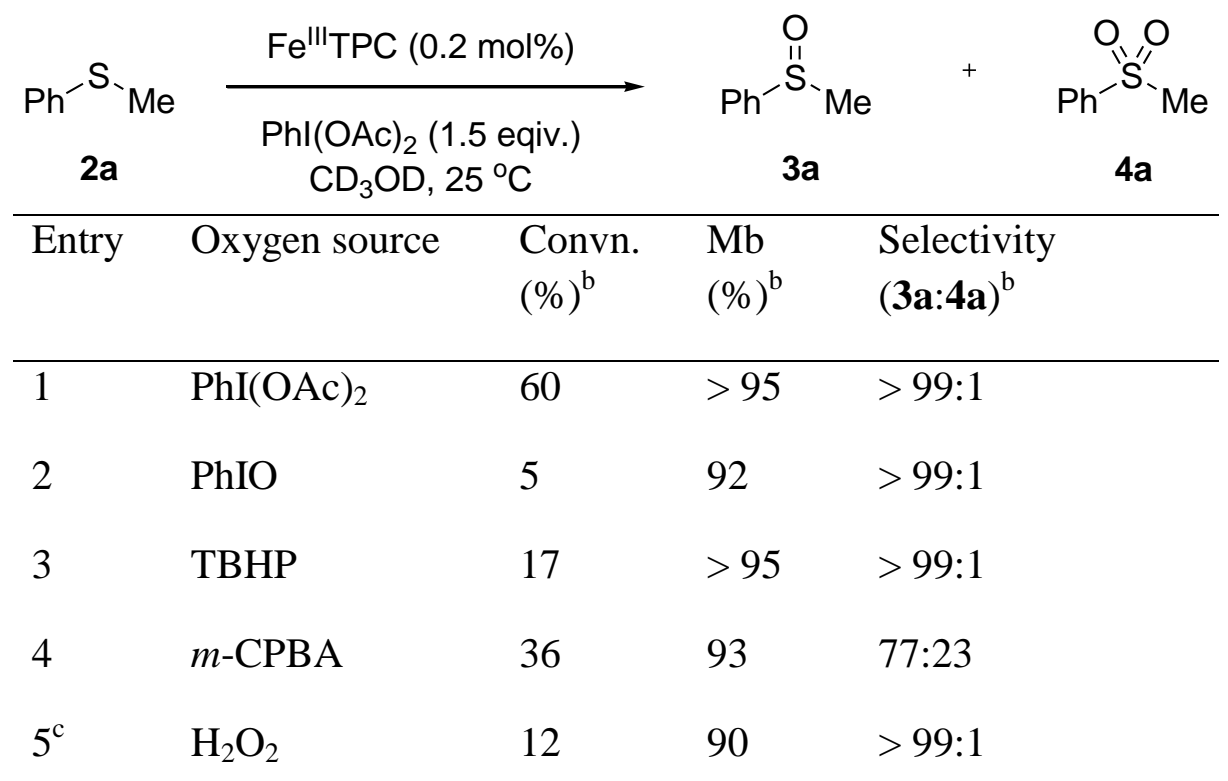

${ }^{\mathrm{a}}$ Unless otherwise noted, all reactions were performed in $\mathrm{CD}_{3} \mathrm{OD}(2 \mathrm{~mL})$ at ca. $23{ }^{\circ} \mathrm{C}$ with a $1: 1.5$ molar ratio of thioanisole versus $\mathrm{PhI}(\mathrm{OAc})_{2}$ and $0.2 \mathrm{~mol} \%$ catalyst at an initial substrate concentration of $0.25 \mathrm{M}$ in the absence of $\mathrm{H}_{2} \mathrm{O}$ and the mixture was stirred for $1 \mathrm{~h}$.

${ }^{\mathrm{b}}$ Conversions (Convn.), mass balance $(\mathrm{Mb})$ and product ratios were determined by ${ }^{1} \mathrm{H}-\mathrm{NMR}$ (JEOL $500 \mathrm{M})$ and by quantitative GC-MS analysis with an internal standard (1,2,4-trichlorobenzene) on the crude reaction mixture after the reaction is quenched by sodium hydroxide solution (consuming all oxygen source).

c $30 \%$ aqueous solution of $\mathrm{H}_{2} \mathrm{O}_{2}$ was used

\subsection{Substrate scope}

Subsequently, the substrate scope of the catalytic sulfoxidations were further explored under optimized conditions. Table 3 lists the oxidized products and corresponding selectivities using 1a 
and $\mathbf{1 b}$ as the catalyst, respectively. In analogy with what we observed for $\mathbf{2} \mathbf{a}$, all catalytic oxidation of substituted thioanisoles proceeded with a quantitative conversion into the corresponding sulfoxides as the only identifiable products (> $99 \%$ by GC). Again, in all cases, no traces of sulfones were detected. Significant for preparative purposes, comparable yields in isolated products were obtained. Some sulfoxidation reactions were scaled up to $5.0 \mathrm{mmol}$ and to our delight, $100 \%$ conversion and over $90 \%$ isolated yield exclusively for sulfoxides were achieved (entries 1, 2 and $6)$.

Table 3. Catalytic oxidation of substituted thioanisoles by iron corrole (1) and $\mathrm{PhI}(\mathrm{OAc})_{2}{ }^{\mathrm{a}}$

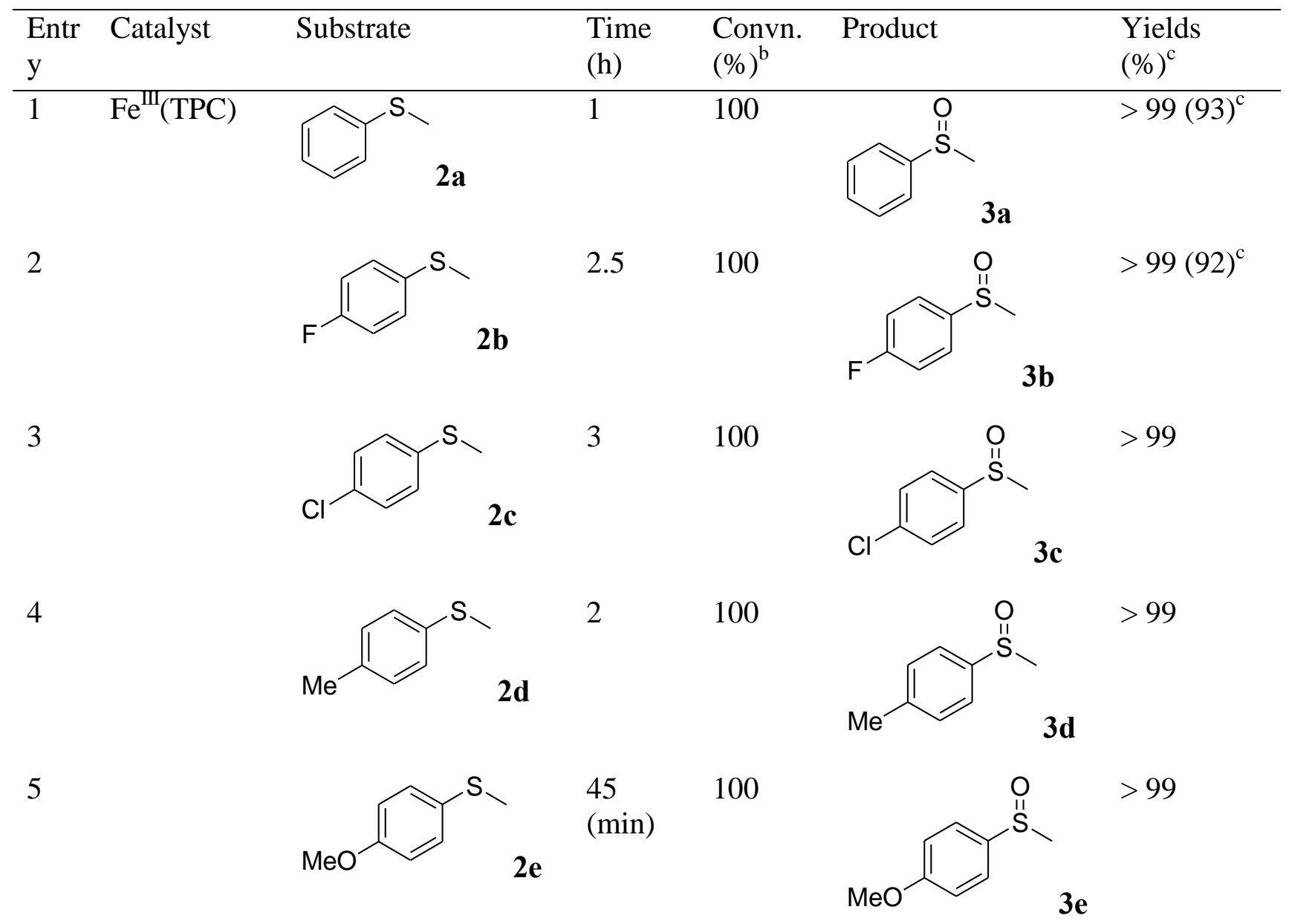


$6 \quad \mathrm{Fe}^{\mathrm{III}}(\mathrm{TPFC})$

3

100<smiles>CS(=O)c1ccccc1</smiles>

7<smiles>CSc1ccc(F)cc1</smiles>

5<smiles>CS(=O)c1ccc(F)cc1</smiles>

8

5.5

100<smiles>CS(=O)c1ccc(Cl)cc1</smiles>

9<smiles>CSc1ccc(C)cc1</smiles>

100<smiles>Cc1ccc(S(C)=O)cc1</smiles>

$>99$

2d

100<smiles>COc1ccc(S(C)=O)cc1</smiles>

\footnotetext{
${ }^{a}$ Unless otherwise specified, all reactions were performed in $\mathrm{CD}_{3} \mathrm{OD}(2 \mathrm{~mL})$ at ca. $23{ }^{\circ} \mathrm{C}$ with 1.5 equiv. of $\mathrm{PhI}(\mathrm{OAc})_{2}(0.75 \mathrm{mmol})$, substrate $(0.5 \mathrm{mmol}), 0.2 \mathrm{~mol} \%$ catalyst in the presence of $\mathrm{H}_{2} \mathrm{O}$ $(4.5 \mu \mathrm{L})$; only sulfoxide was detected by ${ }^{1} \mathrm{H}-\mathrm{NMR}$ and GC analysis of the crude reaction mixture.

${ }^{b}$ Based on the conversion of substrates and determined by ${ }^{1} \mathrm{H}-\mathrm{NMR}$ and quantitative GC-MS analysis with an internal standard (1,2,4-trichlorobenzene) on the crude reaction mixture after the reaction is quenched by sodium hydroxide solution (consuming all oxygen source); material balance $>95 \%$.

${ }^{\mathrm{c}}$ Isolated yield in the parenthesis from a scaled-up reactions with $5 \mathrm{mmol}$ substrate.
}

As evident in Table 3, we have demonstrated that the highly chemoselective and efficient oxidation of sulfides to sulfoxides was achieved by iron(III) corroles with $\mathrm{PhI}(\mathrm{OAc})_{2}$. The slow and steady-state formation of $\mathrm{PhIO}$ in the presence of small amount of water may contribute the enhanced catalytic activity, the stability of the corrole catalyst against degradation, and even 
improved solubility of the oxygen source. Its efficacy for sulfoxidation was further investigated in the oxidation of vinyl sulfides (Table 4). The oxidation of sulfides in the presence of electron-rich double bonds is often problematic with many traditional oxidants and catalytic systems because of interference with epoxidations. With catalysts (1a and $\mathbf{1 b})$ and $\mathrm{PhI}(\mathrm{OAc})_{2}$ in the presence of $\mathrm{H}_{2} \mathrm{O}$, we found that no epoxidation took place and only sulfoxidations were observed in all cases.

However, moderate conversions were observed in some cases (entries 1,2 and 5) mainly due to the catalyst bleaching under those catalytic conditions, as indicated by UV-vis spectroscopic spectra in the end of reactions (see Fig S2 in the supporting information). Similarly, the presence of the hydroxyl group did not disturb the chemoselective oxidation of sulfide and no alcohol oxidation was observed (entry 3-4 and 7-8).

Table 4. Catalytic oxidation of vinyl and hydroxyl sulfides by iron corrole (1) and $\mathrm{PhI}(\mathrm{OAc})_{2}{ }^{\mathrm{a}}$

\begin{tabular}{|c|c|c|c|c|c|c|}
\hline Entry & Catalyst & Substrate & $\begin{array}{l}\text { Time } \\
\text { (h) }\end{array}$ & $\begin{array}{l}\text { Convn. } \\
(\%)^{b}\end{array}$ & Product & $\begin{array}{l}\text { Yields } \\
(\%)^{\mathrm{b}}\end{array}$ \\
\hline 1 & $\mathrm{Fe}^{\mathrm{III}}(\mathrm{TPC})$ & $\mathrm{Ph}^{-\mathrm{S}}$ & 1 & 79 & & 100 \\
\hline 2 & & & 0.5 & 60 & & 100 \\
\hline 3 & & & 1 & 100 & & $>99$ \\
\hline 4 & & $\mathrm{HO}^{-}$ & 0.5 & 100 & & 100 \\
\hline 5 & $\mathrm{Fe}^{\mathrm{III}}$ (TPFC) & $\mathrm{Ph}^{-S}$ & 1 & 71 & & 100 \\
\hline 6 & & & 0.5 & 100 & & 100 \\
\hline
\end{tabular}




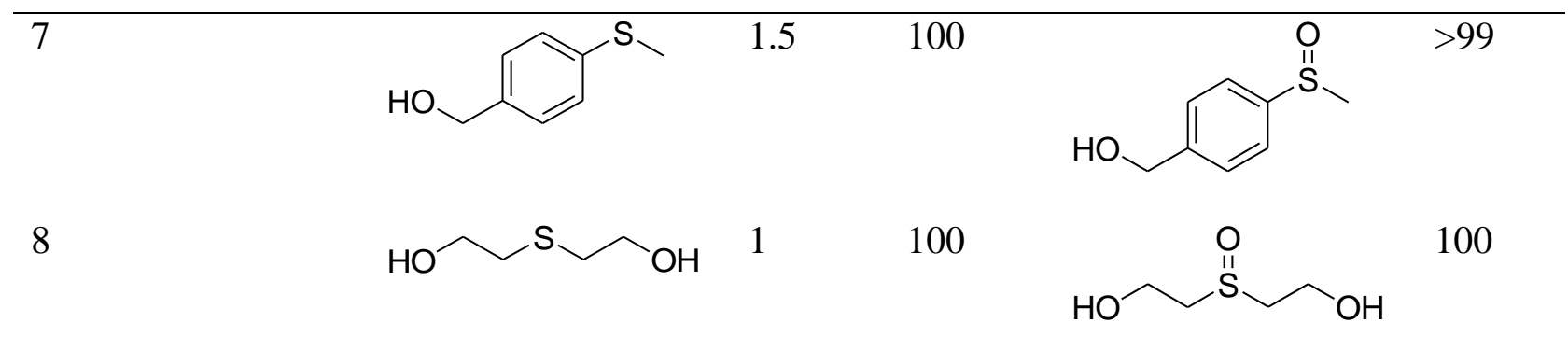

\footnotetext{
${ }^{a}$ Unless otherwise specified, all reactions were performed in $\mathrm{CD}_{3} \mathrm{OD}(2 \mathrm{~mL})$ at ca. $23{ }^{\circ} \mathrm{C}$ with 1.5 equiv. of $\mathrm{PhI}(\mathrm{OAc})_{2}(0.75 \mathrm{mmol})$, substrate $(0.5 \mathrm{mmol}), 0.2 \mathrm{~mol} \%$ catalyst in the presence of $\mathrm{H}_{2} \mathrm{O}$ $(4.5 \mu \mathrm{L})$; only sulfoxide was detected by ${ }^{1} \mathrm{H}-\mathrm{NMR}$ analysis of the crude reaction mixture.

${ }^{\mathrm{b}}$ Based on the conversion of substrates and determined by ${ }^{1} \mathrm{H}-\mathrm{NMR}$ and by quantitative GC-MS analysis with an internal standard (1,2,4-trichlorobenzene) on the crude reaction mixture after the reaction is quenched by sodium hydroxide solution (consuming all oxygen source); material balance $>95 \%$.
}

\subsection{Spectral studies for probing the active intermediate}

High-valent metal-oxo corroles have been proposed as the key intermediates in many metallocorrole-catalyzed reactions.[21, 43] Of note, the possible formation of the highly reactive iron(V)-oxo corrole (5) was reported in previous transient absorption studies.[44, 45] To this end, we conducted the chemical oxidation of $\mathrm{Fe}^{\mathrm{III}}(\mathrm{Cor})$ by $\mathrm{PhI}(\mathrm{OAc})_{2}$ in $\mathrm{CH}_{3} \mathrm{OH}$ in the absence of sulfides to probe the nature of the active oxidizing intermediate. If involvement of a high-valent iron-oxo is operative in current study, one can expect that the formed iron-oxo corroles may behave differently by considering the different electronic environments of the two corrole ligands. In view of its electrophilic nature, the reactivity of $\mathbf{5}$ follows TPFC $>$ TPC. On the other hand, the formation of the transient $\mathbf{5}$ in the electron-deficient TPFC system is apparently less favorable because of the expected high oxidation or energy barrier.

As shown in Figure 2A, addition of 20 equivalents of $\mathrm{PhI}(\mathrm{OAc})_{2}$ resulted in instant conversion of 1a to a short-lived transient (5) that decayed rapidly to an unknown product (6) with a weaker Soret band at $410 \mathrm{~nm}$ and a stronger Q band at $720 \mathrm{~nm}$, characteristic of an iron(IV)-oxo 
corrole radical cation. Direct spectroscopic evidence for such a high-valent iron-oxo corrole radical cation has been reported.[46] It is noteworthy that the UV-vis signal of the transient $\mathbf{5}$ that was instantly formed closely resembled that of the putative corrole-iron(V)-oxo species, which apparently also was formed when the neutral corrole-iron(III) complex was mixed with excess $m$ CPBA.[44] As thermodynamically favored in the less electron-demanding TPC system, iron(V)oxo species 5 might relax to radical cation species 6 by internal electron transfer (ET) from the corrole ligand to the iron.[47] In contrast, the electron-deficient Fe ${ }^{\mathrm{III}}(\mathrm{TPFC}) \mathbf{1 b}\left(\lambda_{\max }=404 \mathrm{~nm}\right)$ was quantitatively converted by excess $\mathrm{PhI}(\mathrm{OAc})_{2}$ (5 to 20 equivalents) to a stable compound with clearly resolved isosbestic points (Fig. 2B). The formed product with an absorption at $\lambda_{\max }=380 \mathrm{~nm}$ was identified as the known bis-corrole-diiron(IV) $\mu$-oxo dimer $\left[\mathrm{Fe}^{\mathrm{IV}}(\mathrm{TPFC})\right]_{2} \mathrm{O}$, which was independently prepared from a reported method and characterized by NMR and UV-vis spectra.[40] As suggested by a previous study,[34] the electron-withdrawing substituents such as F on the corrole ligand are necessary for $\mu$-oxo dimer formation. Using the same procedure by reacting $1 \mathbf{a}$ with a non-halogenated 5,10,15-triphenylcorrole did not give the corresponding $\mu$-oxo products. Presumably, the F groups could stabilize the iron(IV) complex in a dimeric form by reducing the electron density of the metal atom. In the TPFC system, the ET sequence from the highly electrondeficient corrole to the iron is apparently not favored in view of a high redox potential or energy barrier. Due to a slow formation rate by mild $\mathrm{PhI}(\mathrm{OAc})_{2}$, the highly reactive iron(V)-oxo oxidant may react with residual iron(III) precursor in a comproportionation reaction to produce the stable $\mu$ oxo dimer. Previous studies with manganese-oxo species found that porphyrin-manganese(V)-oxo species comproportionate rapidly with manganese(III) species,[48] and corrole-manganese(V)-oxo species reacted with corrole manganese(III) species to give manganese(IV) species.[49] 

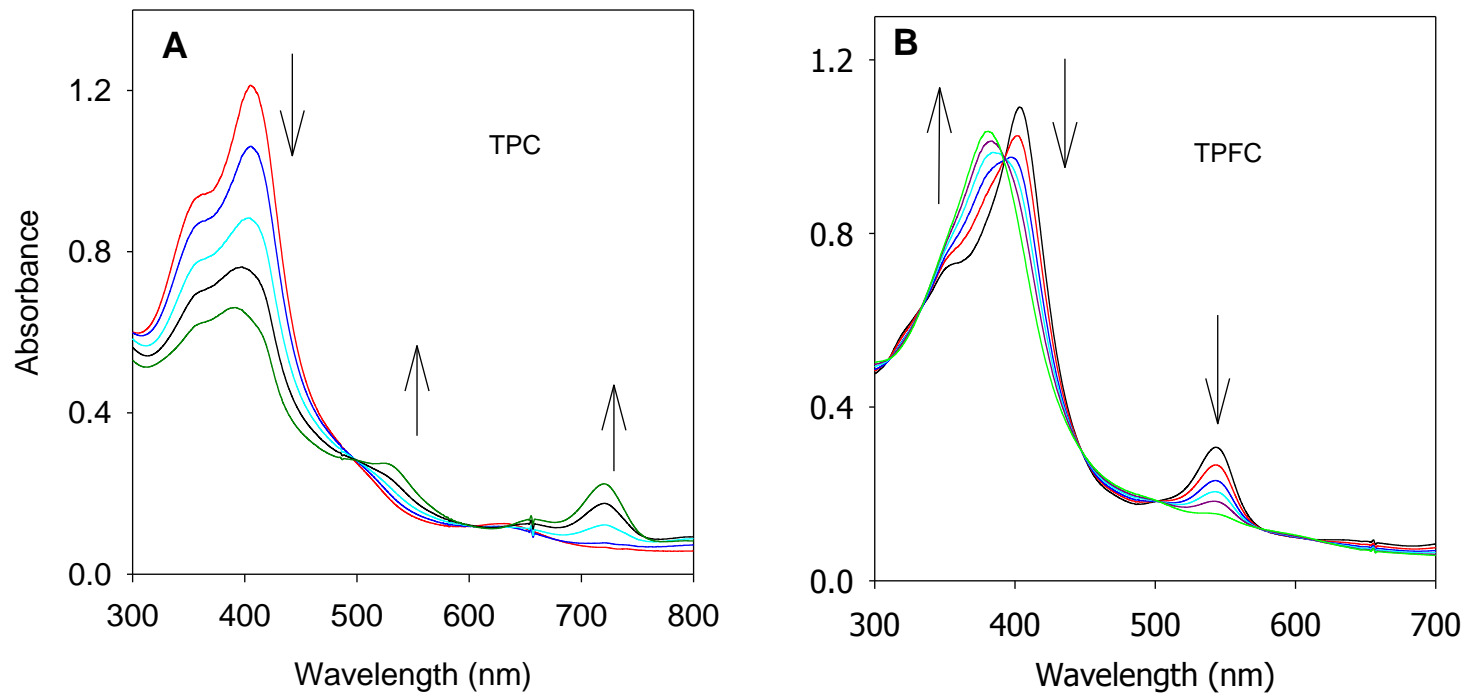

Fig. 2. Time-resolved spectra of the oxidation of (A) $\mathrm{Fe}^{\mathrm{III}}(\mathrm{TPC})$ by $\mathrm{PhI}(\mathrm{OAc})_{2}$ (20 equiv.) over $10 \mathrm{~s}$ and (B) $\mathrm{Fe}^{\mathrm{III}}$ (TPFC) by $\mathrm{PhI}(\mathrm{OAc})_{2}$ (5 equiv.) over $20 \mathrm{~s}$ in anaerobic $\mathrm{CH}_{3} \mathrm{OH}$ at $23 \pm 2{ }^{\circ} \mathrm{C}$.

\subsection{Hammett correlation studies}

The effect of para substituents on the homogeneous iron(III) corrole-catalyzed thioanisole oxidation has been investigated, and provided additional insight into the reaction mechanism. A significant dependence on the electronic properties of the para substituent was observed (Fig. 3). The relative rates $\left(k_{\mathrm{rel}}\right)$ for the catalytic oxidation of several substituted thioanisoles (Y-thioanisole, $\mathrm{Y}=4-\mathrm{MeO}$, 4-Me, 4-F, and 4-Cl) were evaluated by monitoring the product formation (sulfoxides) using GC and ${ }^{1} \mathrm{H}$ NMR (see the Experimental Section). In this work, all catalytic sulfoxidations proceeded with good sulfoxide yields (> 99\%) and mass balance (> 95\%). In all cases, a limiting amount of $\mathrm{PhI}(\mathrm{OAc})_{2}$ was used to keep the conversion less than $20 \%$ to avoid the effect of substrate concentration on the product ratios. Thus, the rate of sulfoxide formation should reasonably reflect the thioanisole reactivity toward the iron corrole-catalyzed oxidations. Figure $3 \mathrm{~A}$ and $3 \mathrm{~B}$ depict a linear correlation $(R=0.99)$ of $\log k_{\text {rel }}\left[k_{\text {rel }}=k(\right.$ Y-thioanisole $) / k($ thioanisole $\left.)\right]$ versus Hammett $\sigma^{+}$ 
substituent constant in both corrole systems. The slope $\left(\rho^{+}\right)$of the plot is -0.95 for TPC and -0.85 for TPFC system, respectively, suggesting the likely involvement of the highly reactive corrole-ironoxo intermediates with the expected electrophilic character. Furthermore, negative $\rho^{+}$value also indicates the transition states for rate-limiting steps involve charge separation. Similar values were also found with the corrole-manganese $(V)$ species with halogen-substituted ligand $\left(\rho^{+}=-1.06\right)$.[43] Consistent with the well-established reactivity-selectivity principle, the more reactive iron(V)-oxo in the TPFC system is less selective $\left(\rho^{+}=-0.85\right)$ than the less reactive one in TPC $\left(\rho^{+}=-0.95\right)$.

Clearly, Hammett correlation studies from the competitive product analysis strongly suggest that the postulated corrole-iron(V)-oxo species[44, 45] as the premier reactive intermediate is plausible even though its definitive detection and assignment needs to be spectroscopically characterized more fully.
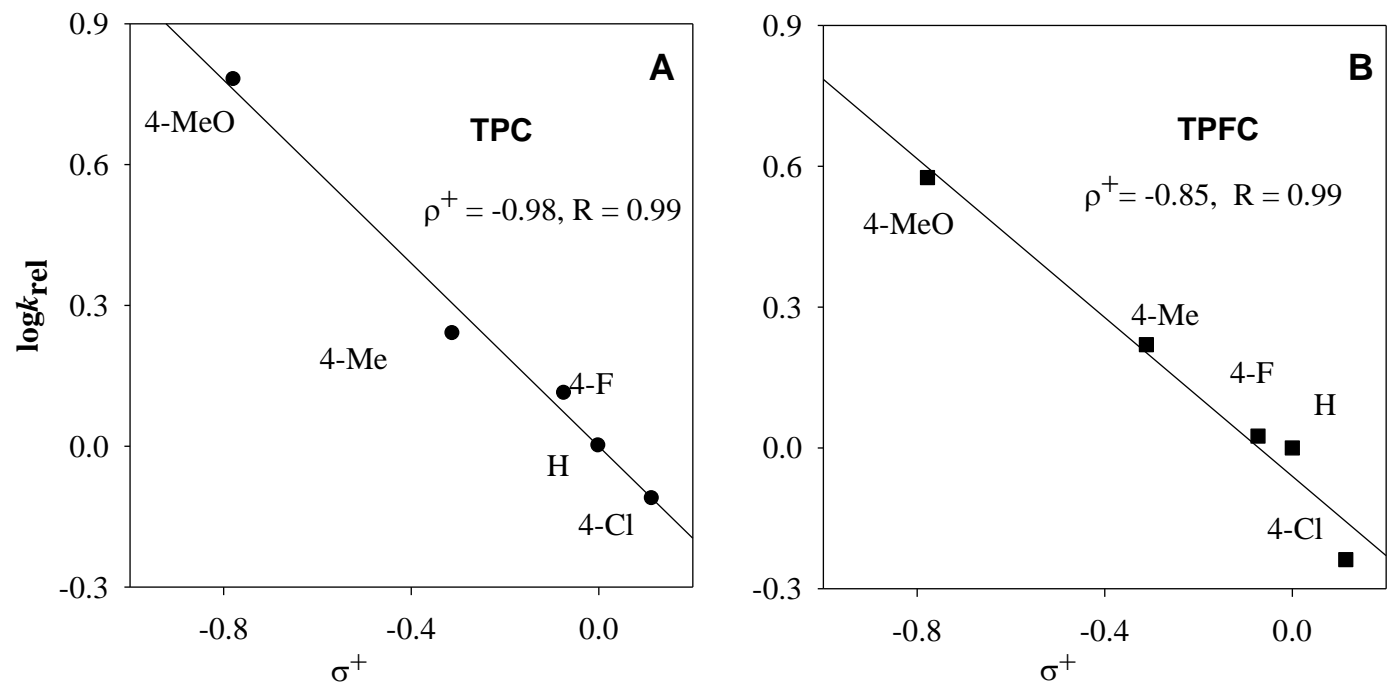

Fig. 3. Hammett correlation studies $\left(\log k_{\mathrm{rel}} \mathrm{vs} \sigma^{+}\right.$) for the iron(III) corrole-catalyzed sulfoxidation of substituted thioanisoles by $\mathrm{PhI}(\mathrm{OAc})_{2}$ in $\mathrm{CH}_{3} \mathrm{OH}$ at $23 \pm 2{ }^{\circ} \mathrm{C}$. (A): $\mathrm{Fe}{ }^{\mathrm{III}}$ (TPC) as the catalyst (B) $\mathrm{Fe}^{\mathrm{III}}$ (TPFC) as the catalyst. 


\section{Conclusion}

In conclusion, we have demonstrated that the corrole-iron(III) complex efficiently catalyzed the oxidation of organic sulfides to sulfoxides with $\mathrm{PhI}(\mathrm{OAc})_{2}$ in the presence of a small amount of water. The iron(III) corrole catalysts exhibit high reactivity, excellent chemoselectivity, and improved stability that is ascribed to a slow and steady-state formation of $\mathrm{PhIO}$ from $\mathrm{PhI}(\mathrm{OAc})_{2}$. The UV-vis mixing and Hammett correlation studies have suggested a putative corrole-iron(V)-oxo intermediate as the active oxidant involved in the catalytic oxidation, which may relax to a radical cation compound through internal ET from corrole to iron or undergo rapid comproportionation reaction with residual iron(III) compound to form a stable iron(IV) $\mu$-oxo dimer (Scheme 2). Further studies to define synthetic applications and characterize the observed transients more fully are underway in our laboratory.

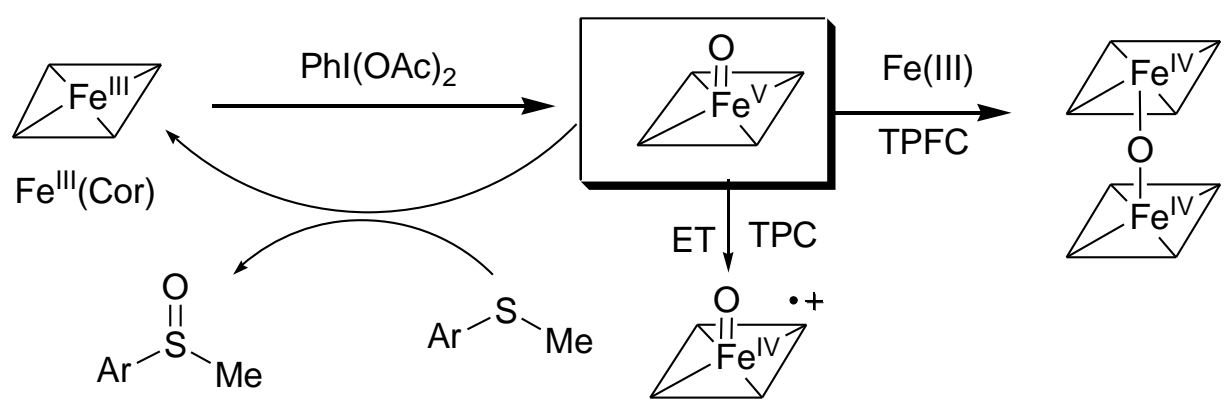

Scheme 2. A proposed catalytic mechanism

\section{ACKNOWLEDGMENTS}

This research is supported by the National Science Foundation (CHE 1464886) and Kentucky EPSCoR program (REG 2015). K. W. Kwong is grateful to the Graduate School of WKU for a Graduate Student Research Fellowship (GSRF). D. Ranburger is thankful to the WKU Office of Research for awarding internal FUSE grants. 
Table of Abbreviations

\begin{tabular}{|l|l|}
\hline Cor & Corrole \\
\hline TPFC & $5,10,15$ - tripentafluorophenylcorrole trianion \\
\hline TPC & $5,10,15$-triphenylcorrole trianion \\
\hline TPFPP & $5,10,15,20$ - tetrapentafluorophenylporphyrin dianion \\
\hline PhIO & iodosylbenzene \\
\hline TBHP & tert-butyl hydrogenperoxide \\
\hline$m$-CPBA & m-chloroperoxybenzoic acid \\
\hline TONs & turnover numbers \\
\hline ET & electron transfer \\
\hline
\end{tabular}

Fig. 1. Time courses of oxidation of thioanisole $(0.5 \mathrm{mmol})$ with $\mathrm{PhI}(\mathrm{OAc})_{2}(0.75 \mathrm{mmol})$ in $\mathrm{CD}_{3} \mathrm{OD}$ $(2 \mathrm{~mL})$ at room temperature catalyzed by $\mathrm{Fe}^{\mathrm{III}}(\mathrm{TPC})(\mathbf{1 a}, 1.0 \mu \mathrm{mol})$ in the presence (circle) or absence (square) of $\mathrm{H}_{2} \mathrm{O}(4.5 \mu \mathrm{L})$. Aliquots were taken at selected time intervals for product analyses with GC.

Fig. 2. Time-resolved spectra of the oxidation of (A) $\mathrm{Fe}^{\mathrm{III}}(\mathrm{TPC})$ by $\mathrm{PhI}(\mathrm{OAc})_{2}$ (20 equiv.) over $10 \mathrm{~s}$ and (B) $\mathrm{Fe}^{\mathrm{III}}$ (TPFC) by $\mathrm{PhI}(\mathrm{OAc})_{2}$ (5 equiv.) over $20 \mathrm{~s}$ in anaerobic $\mathrm{CH}_{3} \mathrm{OH}$ at $23 \pm 2{ }^{\circ} \mathrm{C}$.

Fig. 3. Hammett correlation studies $\left(\log k_{\mathrm{rel}} \mathrm{vs} \sigma^{+}\right.$) for the iron(III) corrole-catalyzed sulfoxidation of substituted thioanisoles by $\mathrm{PhI}(\mathrm{OAc})_{2}$ in $\mathrm{CH}_{3} \mathrm{OH}$ at $23 \pm 2{ }^{\circ} \mathrm{C}$. (A): $\mathrm{Fe}^{\mathrm{III}}$ (TPC) as the catalyst (B) $\mathrm{Fe}^{\mathrm{III}}$ (TPFC) as the catalyst.

Table 1. Catalytic oxidation of thioanisole by iron corroles with iodobenzene diacetate 
Table 2. Catalytic oxidation of thioanisole by iron(III) corrole (1a) with various oxygen sources in the absence of $\mathrm{H}_{2} \mathrm{O}$

Table 3. Catalytic oxidation of substituted thioanisoles by iron corrole (1) and $\mathrm{PhI}(\mathrm{OAc})_{2}$

Table 4. Catalytic oxidation of vinyl and hydroxyl sulfides by iron corrole (1) and $\mathrm{PhI}(\mathrm{OAc})_{2}$

Scheme 1. Catalytic sulfoxidations by iron(III) corrole in the presence of $\mathrm{PhI}(\mathrm{OAc})_{2}$ and water

Scheme 2. A proposed catalytic mechanism

\section{REFERENCES}

[1] A.E. Shilov, G.B. Shulpin, Chem. Rev. 97 (1997) 2879-2932.

[2] J.E. Baeckvall, Modern oxidation methods, 2nd ed., Wiley-VCH Verlag, Weinheim, 2010.

[3] B. Meunier, Chem. Rev. 92 (1992) 1411-1456.

[4] R.A. Sheldon (Ed.), Metalloprophyrins In Catalytic Oxidations, Marcel Dekker, New York, 1994.

[5] C.-M. Che, J.-S. Huang, Chem. Commun. (2009) 3996-4015.

[6] T. Punniyamurthy, S. Velusamy, J. Iqbal, Chem.Rev. 105 (2005) 2329-2363.

[7] P.R. Ortiz de Montellano (Ed.), Cytochrome P450 Structure, Mechanism, and Biochemistry, 3rd ed., Kluwer Academic/Plenum, New York, 2005.

[8] C.M. Carreno, Chem. Rev. 95 (1995) 1717-1760.

[9] S. Caron, R.W. Dugger, S.G. Ruggeri, J.A. Ragan, D.H.B. Ripin, Chem. Rev. 106 (2006) 2943-2989.

[10] P.M. Kowalski, K.; Ossowska, K.; Kolarska, Z., Tetrahedron 61 (2005) 1933-1953.

[11] R. Noyori, M. Aoki, K. Sato, Chem. Commun. (2003) 1977-1986.

[12] L. Yu, Q. Wang, L. Dai, W.Y. Li, R. Chen, M. Mahmooda, H.Y. Liu, C.K. Chang, Chin. Chem. Lett. 24 (2013) 447-449.

[13] E.W. Wojaczynska, J., Chem. Rev. 110 (2010) 4303-4356.

[14] R. Sevvel, S. Rajagopal, C. Srinivasan, N. Ismail Alhaji, A. Chellamani, J. Org. Chem. 65 (2000) 3334-3340.

[15] C. Bolm, F. Bienewald, Angew. Chem., Int. Ed. 34 (1995) 2640-2642.

[16] J. Legros, C. Bolm, Chem. Eur. J. 11 (2005) 1086-1092.

[17] K. Kamamta, T. Hirano, N. Mizuno, Chem. Commun. 45 (2009) 3958-3960.

[18] Y. Imada, T. Naota, Chem. Rec. 7 (2007) 354-361.

[19] Z. Gross, N. Galili, Angew. Chem., Int. Ed. Engl. 38 (1999) 2366-2369.

[20] Z. Gross, N. Galili, L. Simkhovich, I. Saltsman, M. Botoshansky, D. Blaeser, R. Boese, I. Goldberg, Org. Lett. 1 (1999) 599-602.

[21] Z. Gross, H.B. Gray, Adv. Syn. Catal. 346 (2004) 165-170.

[22] I. Aviv, Z. Gross, Chem. Commun. (2007) 1987-1999.

[23] D.P. Goldberg, Acc. Chem. Res. 40 (2007) 626-634.

[24] H.-Y. Liu, M.H.R. Mahmood, S.-X. Qiuc, C.K. Chang, Coord. Chem. Rev. 257 (2013) 1306-1333. 
[25] A.J. McGown, Y.M. Badiei, P. Leeladee, K.A. Prokop, S. Debeer, D.P. Goldberg, in: K.M. Kadish, Smith, K. M., Guilard, R. (Ed.), Handbook of Porphyrin Science, World Scientific Press, 2011.

[26] Z. Gross, G. Golubkov, L. Simkhovich, Angew. Chem. Int. Ed. Engl. 39 (2000) 4045-4047.

[27] B.S. Mandimutsira, B. Ramdhanie, R.C. Todd, H.L. Wang, A.A. Zareba, R.S.

Czernuszewicz, D.P. Goldberg, J. Am. Chem. Soc. 124 (2002) 15170-15171.

[28] H.-Y. Liu, F. Yam, Y.-T. Xie, X.-Y. Li, C.K. Chang, J. Am. Chem. Soc. 131 (2009) 1289012891.

[29] Z. Gross, L. Simkhovich, N. Galili, Chem. Commun. (1999) 599-600.

[30] A. Mahammed, Z. Gross, J. Am. Chem. Soc. 127 (2005) 2883-2887.

[31] A. Mahammed, H.B. Gray, A.E. Meier-Callahan, Z. Gross, J. Am. Chem. Soc. 125 (2003) 1162-1163.

[32] G. Golubkov, J. Bendix, H.B. Gray, A. Mahammed, I. Goldberg, A.J. DiBilio, Z. Gross, Angew. Chem., Int. Ed. 40 (2001) 2132-2134.

[33] H.Y. Liu, T.S. Lai, L.L. Yeung, C.K. Chang, Org. Lett. 5 (2003) 617-620.

[34] R. Zhang, E. Vanover, T.-H. Chen, H. Thompson, Appl. Catal. A 465 (2013) 95-100.

[35] J.P. Collman, A.S. Chien, T.A. Eberspacher, J.I. Brauman, J. Am. Chem. Soc. 122 (2000) 11098-11100.

[36] J.H. In, S.E. Park, R. Song, W. Nam, Inorg. Chim.Acta 343 (2003) 373-376.

[37] W. Adam, S. Hajra, M. Herderich, C.R. Saha-Moller, Org. Lett. 2 (2000) 2773-2776.

[38] T.-H. Chen, K.-W. Kwong, A. Carver, W.L. Luo, R. Zhang, Appl. Catal. A 497 (2015) 121-

126.

[39] B. Koszarna, D.T. Gryko, J. Org. Chem. 71 (2006) 3707-3717.

[40] L. Simkhovich, A. Mahammed, I. Goldberg, Z. Gross, Chem. Eur. J. 7 (2001) 1041-1055.

[41] L. Simkhovich, I. Goldberg, Z. Gross, Inorg. Chem. 41 (2002) 5433-5439.

[42] L. Mahmoudi, D. Mohajer, R. Kissner, W.H. Koppenol, Dalton Transactions 40 (2011) 8695-8700.

[43] A. Kumar, I. Goldberg, M. Botoshansky, Y. Buchman, G. Z., J. Am. Chem. Soc. 132 (2010) $15233-15245$.

[44] D.N. Harischandra, R. Zhang, M. Newcomb, J. Am. Chem. Soc. 127 (2005) 13776-13777.

[45] D.N. Harischandra, G. Lowery, R. Zhang, M. Newcomb, Org. Lett. 11 (2009) 2089-2092.

[46] A.J. McGown, W.D. Kerber, H. Fujii, D.P. Goldberg, J. Am. Chem. Soc. 131 (2009) 80408048 .

[47] T.S. Chen, N. Asiri, K.K. Kwong, J. Malone, R. Zhang, Chem. Commun. 51 (2015) 99499952.

[48] R. Zhang, J.H. Horner, M. Newcomb, J. Am. Chem. Soc. 127 (2005) 6573-6582.

[49] R. Zhang, D.N. Harischandra, M. Newcomb, Chem. Eur. J. 11 (2005) 5713-5720. 


\section{Figure(s)}

Figure 1

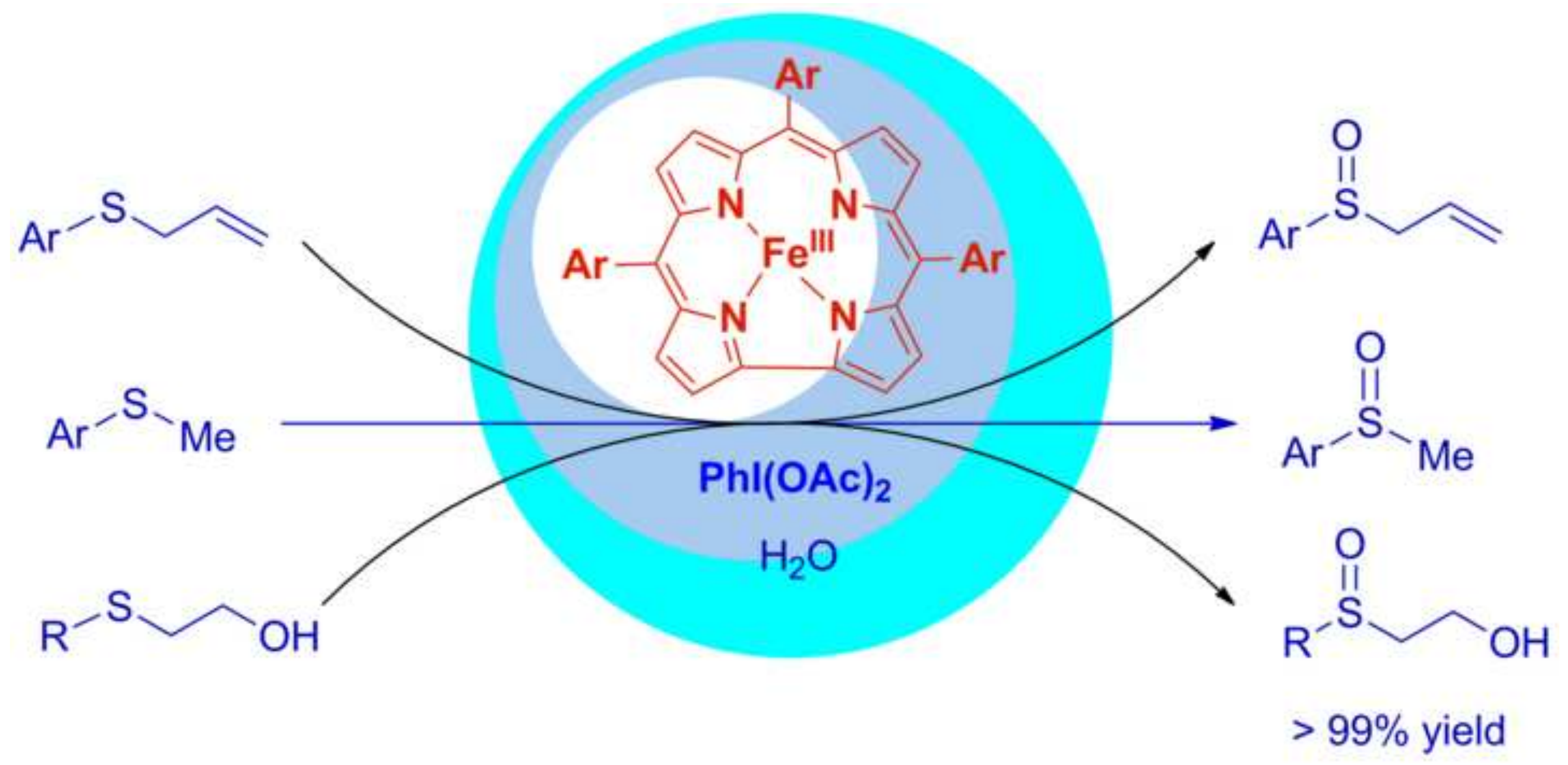




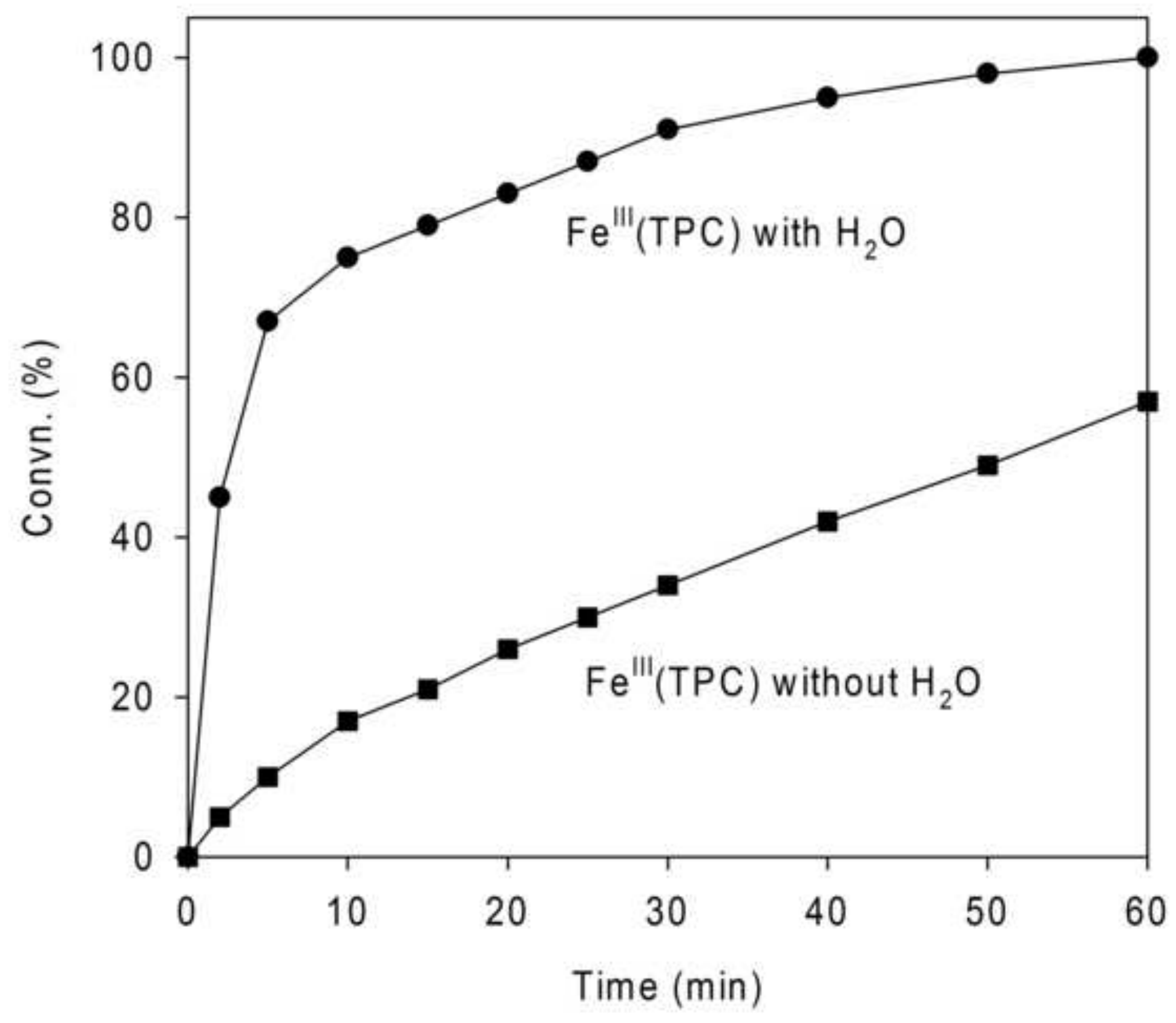



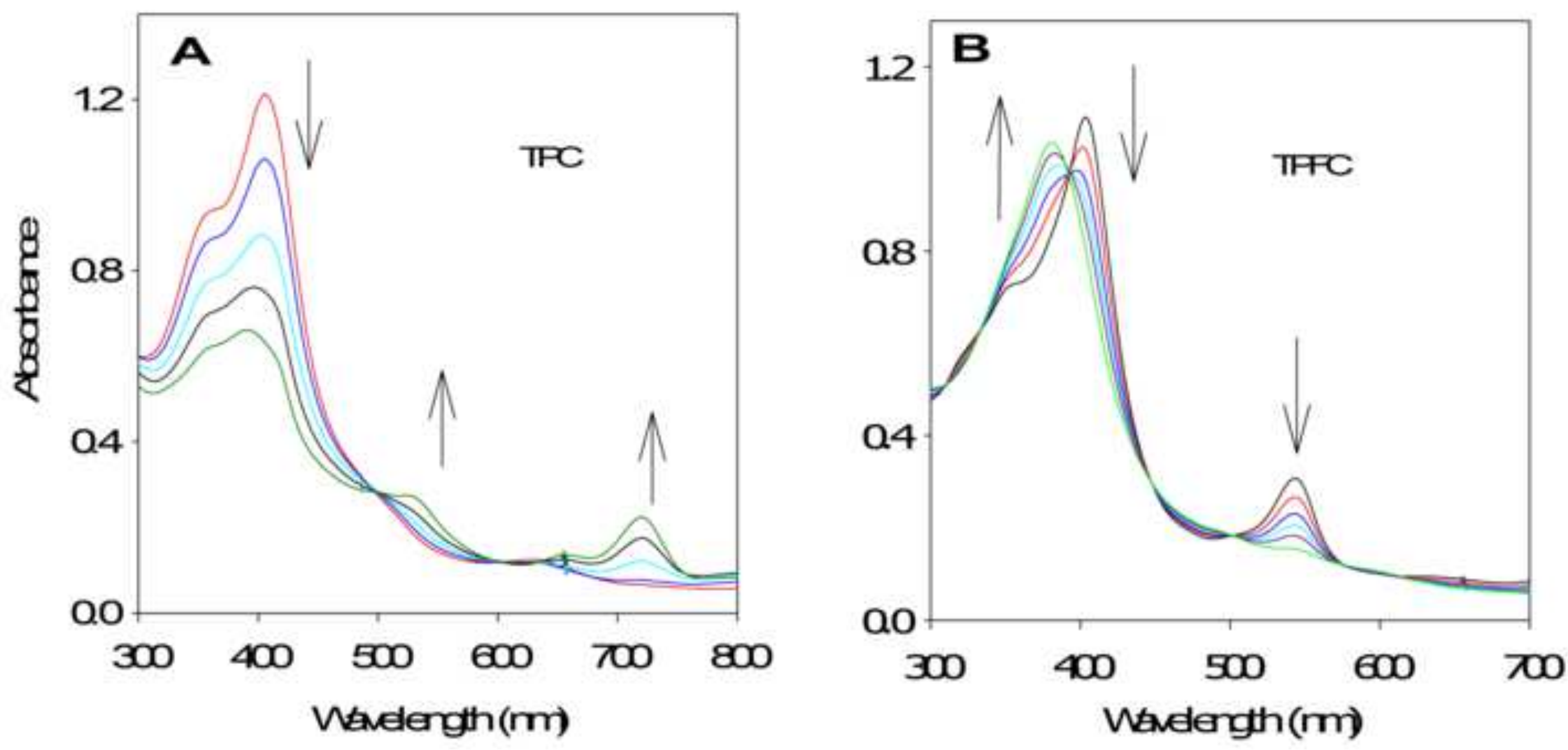

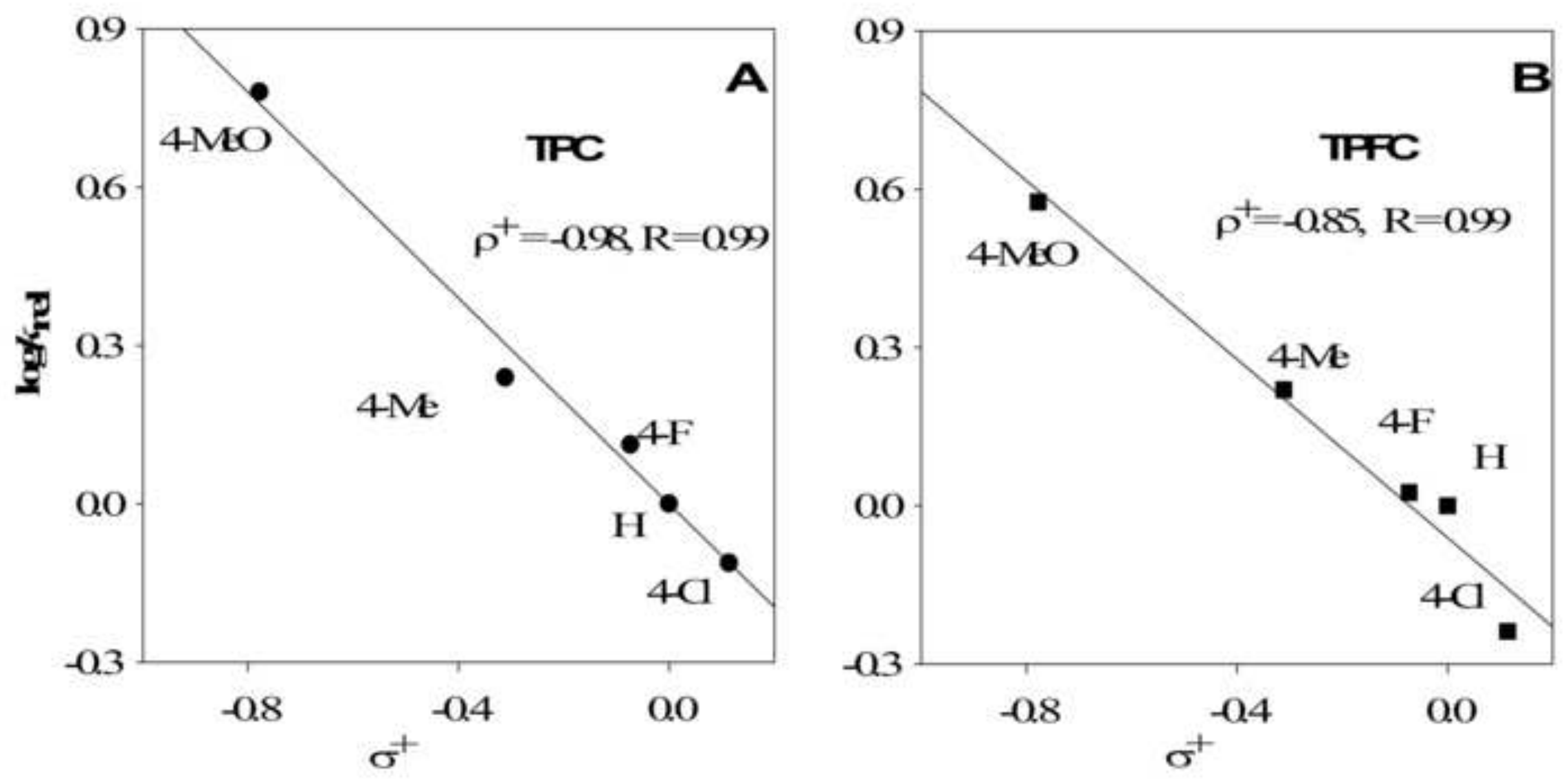


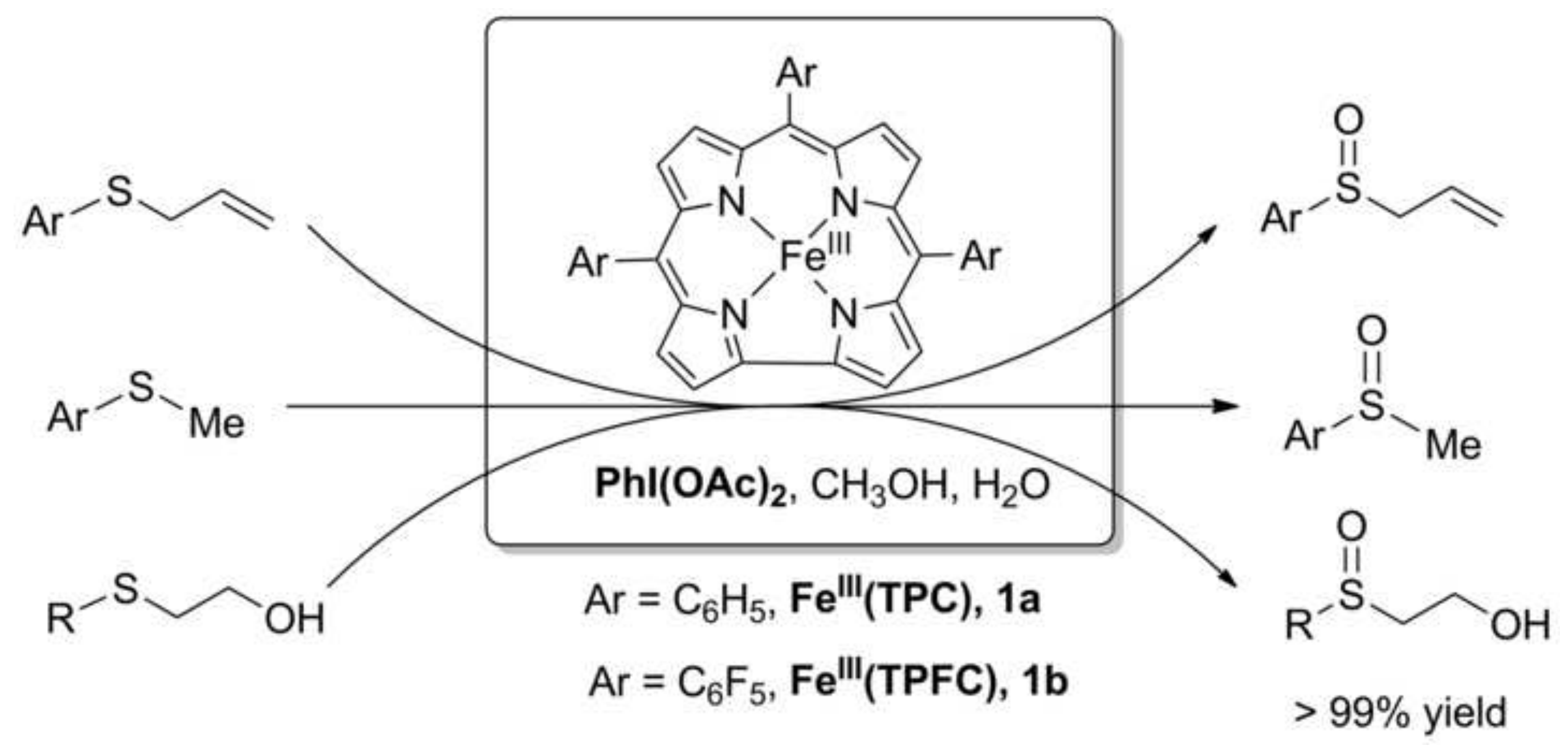




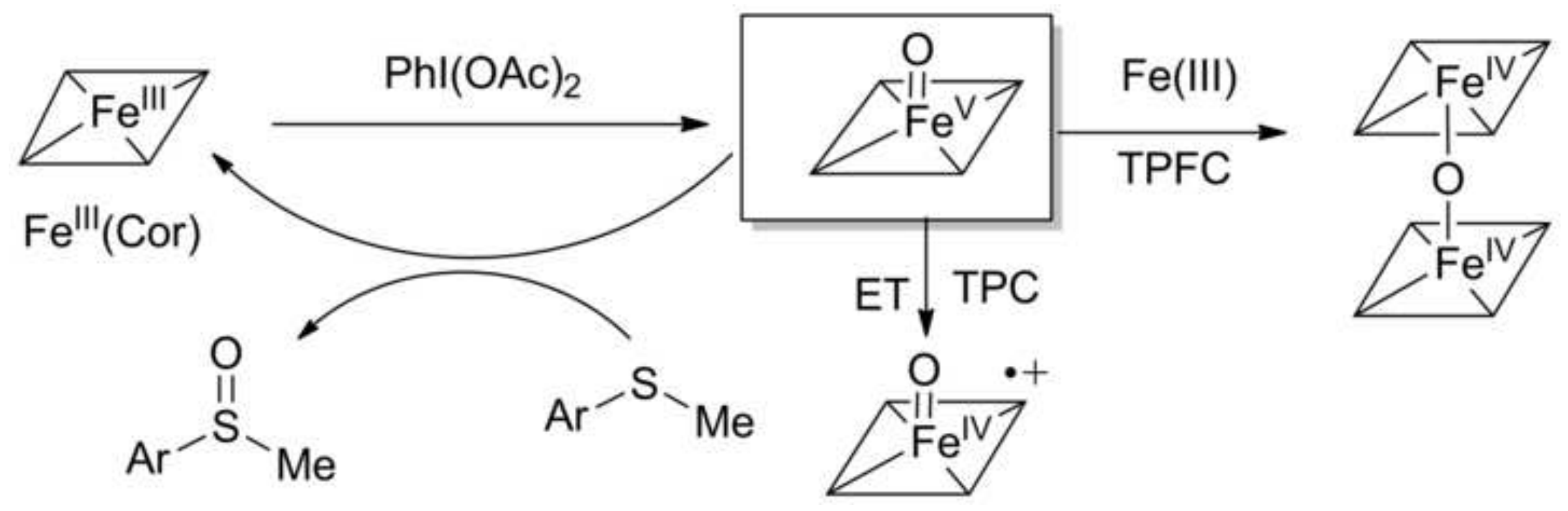




\section{Graphic Abstract:}

Iron(III) corroles catalyze highly efficient and chemoselective sulfoxidations with iodobenzene diacetate as the promising oxygen source. Various substituted thioanisoles, vinyl sulfides, and hydroxyl sulfides can be efficiently oxidized to sulfoxides with quantitative conversions and excellent chemoselectivies.

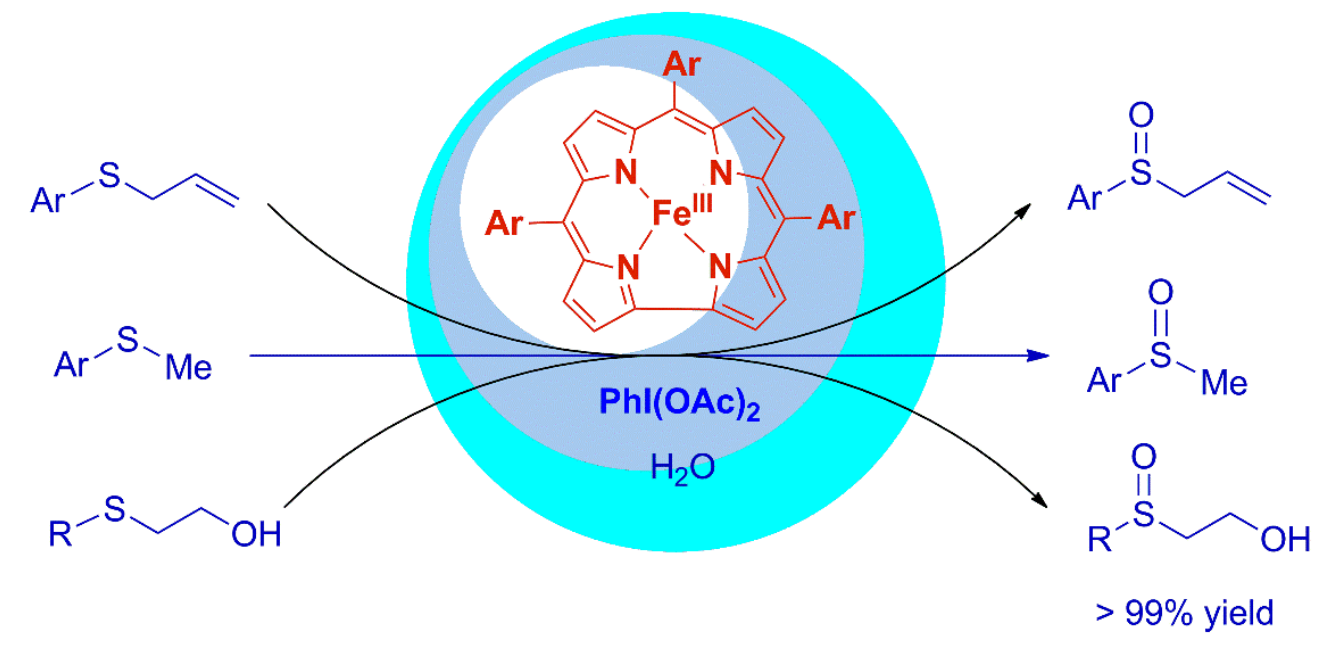


Iron(III) corroles catalyze highly efficient and chemoselective sulfoxidations with iodobenzene
diacetate as the promising oxygen source.

Iron(III) corroles catalyze highly efficient and chemoselective sulfoxidations with iodobenzene
diacetate as the promising oxygen source.

diacetate as the promising oxygen source.

diacetate as the promising oxygen source. Iron(III) corroles catalyze highly efficient
diacetate as the promising oxygen source.

Iron(III) corroles catalyze highly efficient
diacetate as the promising oxygen source

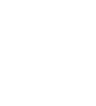

diacetate as the promising oxygen source.

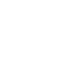

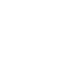

